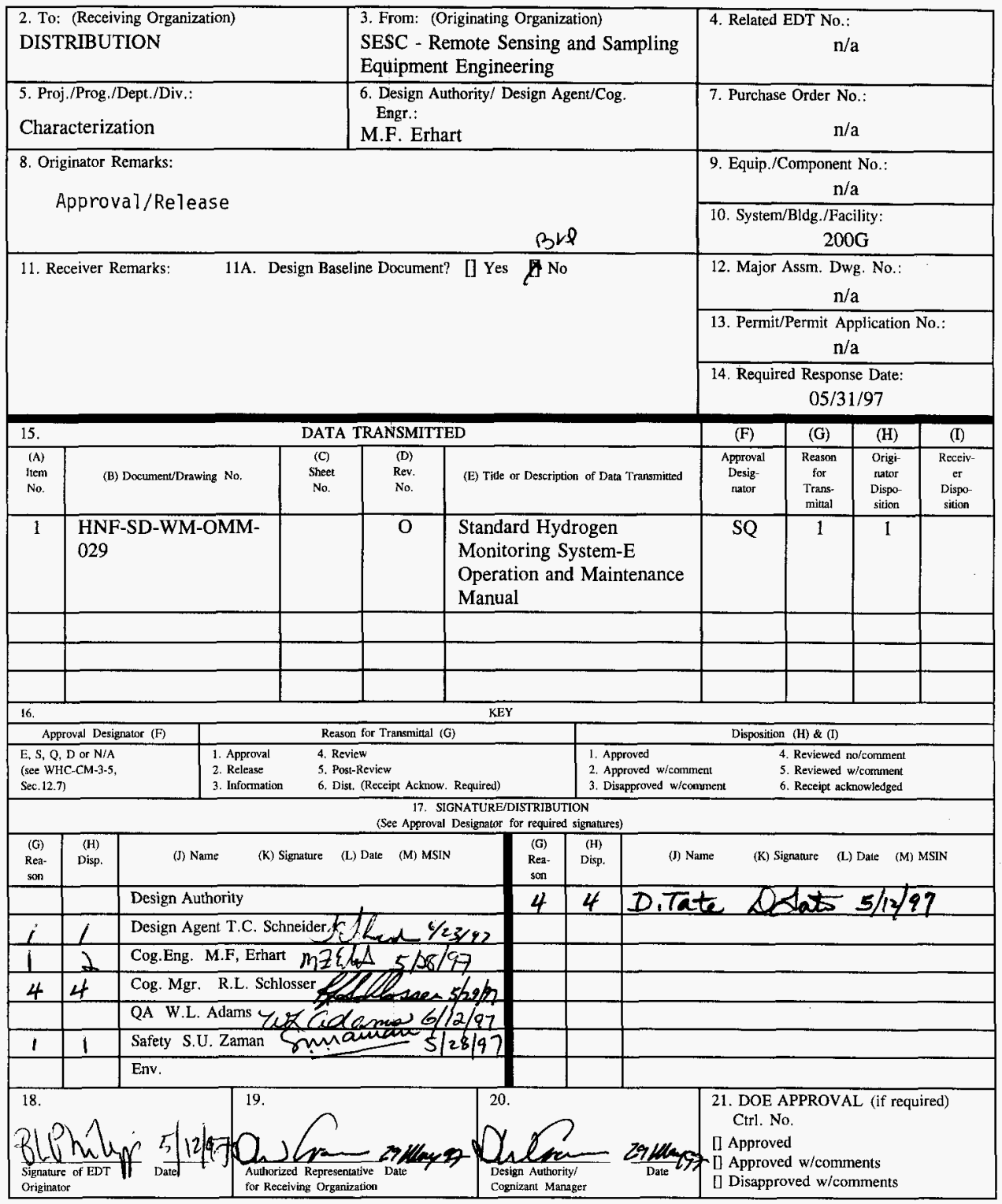




\section{STANDARD HYDROGEN MONITORING SYSTEM- E OPERATION and MAINTENANCE MANUAL}

\section{T. C. Schneider}

Numatec Hanford Company. Richland, WA 99352

U.S. Department of Energy Contract DE-AC06-96RL13200

EDT/ECN: No. 619514 UC: 2030

Org Code: UC200000 Charge Code: N2022

B\&R Code: EW3120072 Tota1 Pages: 38

Key Words: Standard Hydrogen Monitoring System (SHMS)

Abstract:

Standard-E operation manual for the Standard Hydrogen Monitoring System.

TRADEMARK DISCLAIMER. Reference herein to any specific commercial product, process, or service by trade name, trademark, manufacturer, or otherwise, does not necessarily constitute or imply its endorsement, recommendation, or favoring by the United States Government or any agency thereof or its contractors or subcontractors

Printed in the United States of America. To obtain copies of this document, contact: WHC/BCS Document Control Services, P. O. Box 1970. Mailstop H6-08, Richland WA 99352. Phone (509) 372-2420; Fax (509) 376-4989.
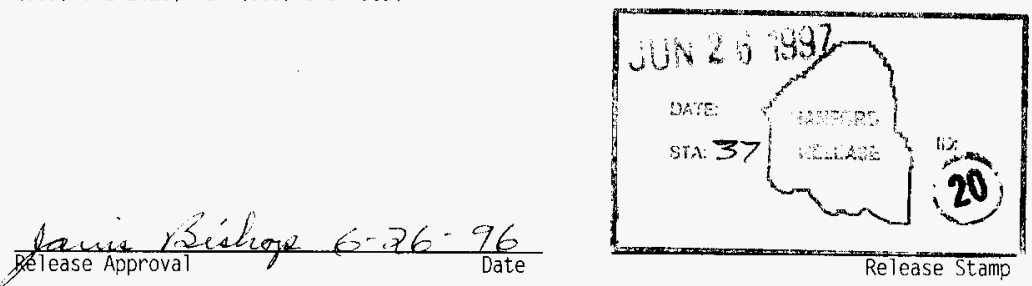

\section{Approved for Public Release}


HNF-SD-WM-OMM-029, REV. 0

PAGE 1 OF 37

STANDARD HYDROGEN MONITORING SYSTEM-E

OPERATION AND MAINTENANCE MANUAL

HNF-SD-WM-OMM-029

REV. 0

Impact Level SQ

Issued by

TWRS Safety Special Projects

June 1997 


\section{TABLE OF CONTENTS}

1.0 GENERAL EQUIPMENT INFORMATION $\ldots \ldots \ldots \ldots \ldots \ldots \ldots$

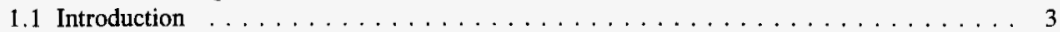

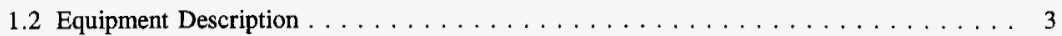

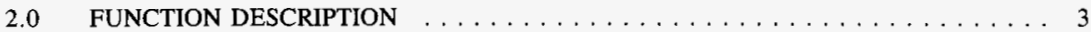

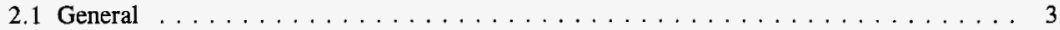

3.0 TERMS AND DEFINITIONS $\ldots \ldots \ldots \ldots \ldots \ldots \ldots \ldots \ldots$

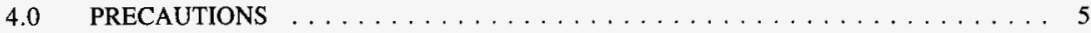

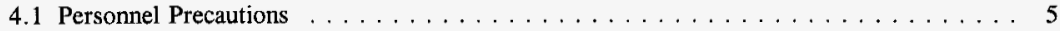

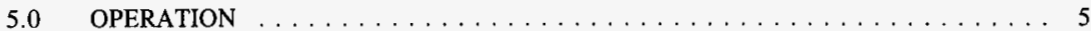

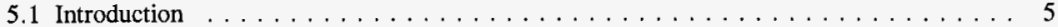

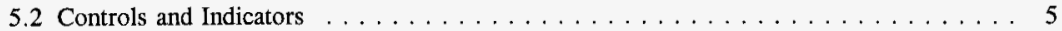

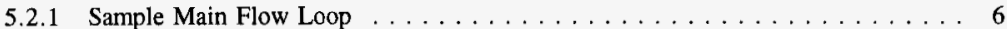

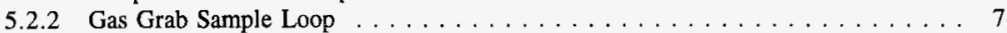

5.2 .3 Multi-gas Analyzer Sample Loop . . . . . . . . . . . . . . . . . . . . 8

5.2 .4 Gas Chromatograph Sample Loop . . . . . . . . . . . . . . . . . . 8

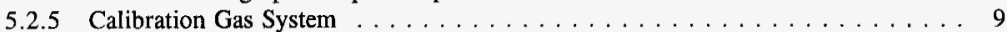

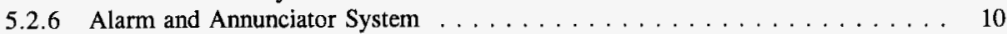

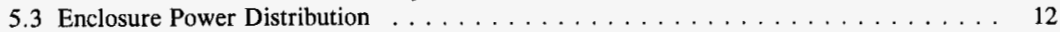

5.3.1 Heat Trace and Environmental Control $\ldots \ldots \ldots \ldots \ldots \ldots$

6.0 OPERATING PROCEDURES $\ldots \ldots \ldots \ldots \ldots \ldots \ldots \ldots \ldots \ldots \ldots$

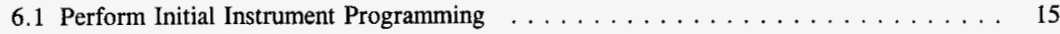

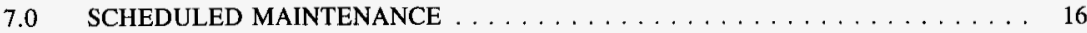

7.1 Instrument Calibration Procedures $\ldots \ldots \ldots \ldots \ldots \ldots$

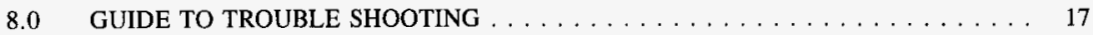

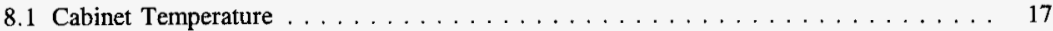

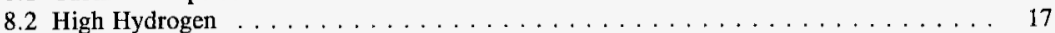

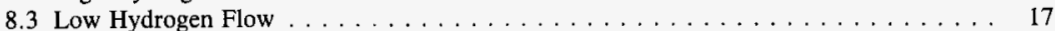

8.4 Gas Temp Low . . . . . . . . . . . . . . . . . . . . . . 18

8.5 Programmable Logic Controller $\ldots \ldots \ldots \ldots \ldots \ldots \ldots$

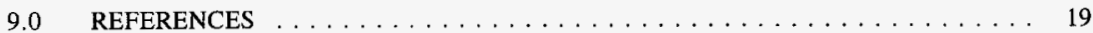

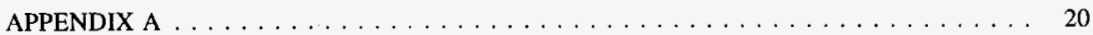

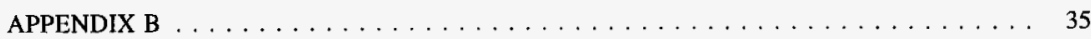




\section{STANDARD HYDROGEN MONITORING SYSTEM-E OPERATION AND MAINTENANCE MANUAL}

\subsection{GENERAL EQUIPMENT INFORMATION}

\subsection{Introduction}

The purpose of this document is to provide information for the operation and maintenance of the Standard Hydrogen Monitoring System-E (SHMS-E) used in the 200E and 200W area tank farms on the Hanford Site. This provides information specific to the mechanical operation of the system and is not intended to take the place of a Plant Operating Procedure. However, it does provide more information on the system than a Plant Operating Procedure. The intent here is that the system is started up by a technician or engineer who has completed tank farms training course for SHMS, and then the only actions performed by Operations will be routine log taking. If any problems not addressed by the operating procedure are encountered with the unit, engineering should be contacted.

\subsection{Equipment Description}

Refer to WHC-SD-WM-SDD-077, Standard-E Hydrogen Monitoring System Design Description (Schneider) for a detailed description of the individual components.

\subsection{FUNCTION DESCRIPTION}

\subsection{General}

The SHMS-E normal and with the analytical equipment installed (referred to as the SHMS-E +) were designed together as an expandable gas monitoring system, and have the same basic cabinet, wiring, tubing, and layout design. The normal SHMS-E will monitor Hydrogen using electrochemical cells like a basic SHMS, but will not have the additional analytical gas monitors installed [Brüel\&Kjær (B\&K) photo-acoustic spectrometer, Microsensor Technology Inc. (MTI) dualcolumn gas chromatograph, and associated computers] though they may be installed in the future with minimal hardware changes. The SHMS-E with the analytical equipment (SHMS-E+) will monitor for hydrogen using electro-chemical cells like the normal SHMS-E, plus use gas analyzers to measure gas concentrations in selectable ranges approximately: Hydrogen (3-100,000 ppm); Nitrous Oxide (10-4,000 ppm); Ammonia (10-10,000 ppm) and Methane (10-4,000 ppm).

An electronically controlled grab sampler has replaced the manually operated sample system that was used in the original SHMS enclosure. Samples can now be operator or automatically initiated. Automatic initiation occurs based on the high hydrogen alarm level. Once a sample is obtained it is removed from the sampler and transported to a laboratory for analysis. This system is used to identify other gaseous constituents which are not measured by the hydrogen monitor. The design does not include any remote data acquisition or remote data logging equipment but will be connected to HLAN for remote logging and provides a 4-20 mA dc process signals, and discrete alarm contacts, that can be utilized for remote data logging and alarming when desired. 
The SHMS-E arrangement consists of design modifications (piping, valves, filters, supports) to the SHMS-C arrangement necessary for the installation of a Brüel\&Kjær (B\&K) photo-acoustic spectrometer Multi-gas analyzer and a second analysis column in the dual column gas chromatograph with the associated sample and calibration gas lines. Additionally, ports have been provide for future Fourier Transform Infrared Spectrometer (FTIR) expansion. The B\&K multigas analyzer will provide real time, analytical quality, specific ammonia measurements in low and medium range concentrations. The first column of the gas chromatograph will provide real time, analytical quality, specific hydrogen measurements in low and medium range concentrations. The second column of the gas chromatograph will provide real time, analytical quality, specific methane and nitrous oxide measurements in low and medium range concentrations.

The normal SHMS-E system is designed to sample process gasses that are classified by NEC code as Class I, Div I, Group B. The analytical equipment have been qualified by the Flammable Gas Evaluation Advisory Board (FGEAB) for use to measure tank vapor space defined by the Ignition Control Set (ICS2)

\subsection{TERMS AND DEFINITIONS}

3.1 AIR CONDITIONER UNIT (ACU)

3.2 ABSOLUTE SYSTEM PRESSURE (AP)

3.3 CIRCUIT BREAKER (CB)

3.4 COUNTER CLOCKWISE (CCW)

3.5 CUBIC FEET PER HOUR (CFH)

3.6 CERTIFIED VENDOR INFORMATION (CVI)

3.7 CLOCKWISE (CW)

3.8 DIFFERENTIAL PRESSURE (DP)

3.9 FLAMMABLE GAS EVALUATION ADVISORY BOARD (FGEAB)

3.10 FLOW ALARM SWITCH LOW (FASL)

3.11 FLOW CONTROL VALVE (FCV)

3.12 FLOW INDICATING TRANSMITTER (FIT)

3.13 FULL SCALE (FS)

3.14 FUSED SWITCH (FU)

3.15 GAS CHROMATOGRAPH (GC)

3.16 HEATER TEMPERATURE CONTROL (HTR)

3.17 HYDROGEN RECORDER (NE)

3.18 IGNITION CONTROL SET (ICS2) 
3.19 INCHES OF WATER $\left(\mathrm{IN} \mathrm{H}_{2} \mathrm{O}\right)$

3.20 LIGHT EMITTING DIODE (LED)

3.21 LITER PER HOUR (LH)

3.22 MANUAL VALVE (MV)

3.23 MILLIAMP (MA)

3.24 NON-LATCHING (NL)

3.25 PROGRAMMABLE LOGIC CONTROLLER (PLC)

3.26 STANDARD CUBIC FEET PER MINUTE (SCFM)

3.27 STANDARD HYDROGEN MONITORING SYSTEM-E (SHMS-E)

3.28 STANDARD LITER PER MINUTE (SLM)

3.29 TERMINAL BOARD (TB)

3.30 THERMAL CONDUCTIVITY DETECTOR (TCD)

\subsection{PRECAUTIONS}

\subsection{Personnel Precautions}

4.1.1 In case of fire or other emergency in the monitoring enclosure, all power to the enclosure shall be secured by opening the local disconnect that serves the enclosure as identified in Tank Farm Plant Operating Procedure, T0-040-041.

4.1.2 If it becomes necessary to isolate the enclosure from the tank it can be accomplished by closing the respective sample and return valves as identified in Tank Farm Plant Operating Procedure, T0-040-041.

\subsection{OPERATION}

\subsection{Introduction}

This operating procedure is a generic procedure for several different units.

\subsection{Controls and Indicators}

Refer to H-14-100837, Standard-E Hydrogen Monitoring System Cabinet Assembly for the location of the various components referred to in this section.

Appendix B contains all of the SHMS-E alarm and control set points, normal expected values, tolerances, etc. 


\subsubsection{Sample Main Flow Loop}

The sample main flow loop provides primary monitoring for hydrogen. The hydrogen sensors used (NE-054 and NE-055) are electrochemical cells that provide an electrical signal proportional to the hydrogen partial pressure in the gas sample. A pressure gauge (PI-053) displays the sample line pressure for system flow calculations and as a troubleshooting aid.

The main loop flow is continuously monitored. The sample gas flow monitoring system consists of an in-line laminar flow element (FE-057) and a differential pressure transmitter (FIT-057) which measures the pressure drop across the flow element. As sample gas flows through the flow element, the transmitter generates a 4-20 milliamp signal proportional to the gas flow rate. The flow through the sample main flow loop can be manually controlled with a flow control valve (SV-024). This valve, in conjunction with the sample gas flow monitor is provided as an aid to tank farm personnel to ensure that there is adequate flow through the main sampling loop.

Two capped stubs with system valving (SV-016, SV-080, SV-081) are provide on the main sample line for potential Fourier Infrared Spectrometer (FTIR) system development.

Before the sample gas enters the hydrogen sensor it is first bypassed through a moisture membrane filter (FLT-050), then filtered through three series filters. The first particulate filter (FLT-052) is a 25 micron particulate and moisture filter, the next two (FLT-053, FLT-054) are .2 micron particulate filters. These filters remove moisture and trap any potentially radioactive particulate contamination from entering the rest of the piping.

If a decrease in sample flow occurs, there are two possible causes: 1 . No sample flow due to sample pump failure. 2. Sample flow reduction due to a plugged particulate filter. The decrease in flow due to plugged filters would most likely be a slow process, unless a tank event produced a large amount of airborne contaminants.

The differential pressure drop across the series combination of the three inlet filters is an indication of a plugged inlet filter. As the filters become clogged this pressure drop will increase. This pressure drop is measured by the differential pressure indicator (PDI-051). Since it measures the pressure drop across all three filters it is not possible to determine which of the three filters has clogged. It is advisable to replace all three if a problem develops. Replacing the inlet filters will require isolating the SHMS enclosure from the tank and disconnecting the filters from the associated piping. Health Physics technical support and a Radiological Work Permit will be required. 


\subsubsection{Gas Grab Sample Loop}

A gas grab sample loop has been included in this design. It is composed of two series connected gas collection cylinders which are connected to the sample stream by two solenoid operated valves. This system allows operator initiated or automatic grab sampling. In operator initiated grab sampling, the operator collects gas specimens by depressing a push button. For an automatic grab sample, the Programmable Logic Controller (PLC) automatically initiates a grab sample cycle when the hydrogen concentration exceeds the high hydrogen alarm set point. In either case, once a grab sample is obtained it is important that the manual cylinder valves are shut as soon as possible once a sample is obtained. This will minimize any possible loss of sample from the cylinders.

Note however that in the case of an automatically initiated grab sample cycle upon a high hydrogen alarm, the tank farm area is potentially unsafe. The operator should remotely verify low hydrogen levels before entry into the affected tank farm.

Once a sample is obtained, the sampler will not respond to future high hydrogen events or operator initiated sampling until manually reset by an operator. This feature was incorporated to prevent the loss of an automatic grab sample due to a subsequent hydrogen event or an operator initiated grab sample; however the Reset Sampler function may be implemented at any time terminating the current sample cycle.

Leak checking of the grab sample system is relatively easy. The gas cylinders are inserted in the assembly using O-ring seal vacuum tube fittings. Once installed the individual bottle isolation valves are opened and a leak check of the system is performed. This is done by shutting SV-005, SV-009, and SV-010 and noting the steady state pressure reading on PI-053. Once noted, SV-015 and SV-025 are closed and the pressure gauge is monitored for five minutes. Any pressure decrease is noted. Next, SV-015 and SV-025 are opened and the grab sample button is depressed. Again, the steady state pressure reading on PI-053 is noted and then SV-015 and SV-025 are closed. Again, the pressure gauge is monitored for five minutes and any pressure decrease greater than what was noted when the sample loop was isolated indicates that there is a leak in the sample loop between the solenoid valves. The valves utilized must be restored to operating condition following the Leak Test.

Operator initiated grab sample collection is performed by depressing the Grab Sample push button. This causes the electrically operated isolation valves (SOV-050 and SOV051) to open and begin the sampling process. The flow rate through the cylinders is manually controlled with the flow control valve FCV-052 which is part of flow indicator FIV-052. After five minutes the electrically operated isolation valves automatically close. To remove the cylinders for sample analysis, shut the individual gas cylinder isolation valves and then remove the gas cylinders under an appropriate Radiological Work Permit and Health Physics Technician supervision.

Once the cylinders are removed, a new set can be inserted into the assembly as discussed previously, the sampler is then reset and a leak check is performed. 


\subsubsection{Multi-gas Analyzer Sample Loop}

A B\&K photo-acoustic spectrometer multi-gas analyzer can be installed as required and utilized for part-per-million (ppm) analysis of ammonia concentration.

The multi-gas analyzer flow loop is initiated through the first moisture membrane filter (FLT-050) on the main sample line. The multi-gas analyzer flow loop sample return merges into the main line after the first 25 micron particulate filter (FLT-052) on the main sample line.

A moisture membrane filter (FLT-050) allows a liquid free sample to be drawn through a branch off the main sample line. Maintenance isolation valves (SV-009, SV-010) are provided at the loop inlet and outlet respectively. The selection of sample or calibration gas is determined by a solenoid controlled 3-way sample valve (SOV-071) in conjunction with the calibration gas isolation solenoid controlled valve (SOV-073).

A moisture membrane filter (FLT-050) with a bypass flow is installed on the main sample line. It is used to provide a dry analysis sample from the main flow loop through a reducer to a $1 / 4$ " line for the multi-gas analyzer.

The flow goes through a solenoid controlled 3-way valve (SOV-071) then through a reducer to a $4 \mathrm{~mm}$ line which goes into the sample inlet on a Brüel\&Kjær (B\&K) photoacoustic spectrometer multi-gas analyzer (NIT-052). The sample flow is passed through the $B \& K$ and exits to a sample return line. The sample merges with the main sample loop previous to the second particulate filter. Isolation valves (SV-009) and (SV-010) are provided for the multi-gas analyzer flow loop.

\subsubsection{Gas Chromatograph Sample Loop}

A Dual Column Gas Chromatograph can be installed and utilized for ppm to percent analysis of hydrogen concentration.

The Gas Chromatograph (GC) flow loop is initiated past the three filters on the main sample line. The GC flow loop sample return merges into the main line after the Main Sample Flow isolation valves, just previous to the sample pump. The GC inlet pressure and differential pressure are manually selected and locally indicated. The sample gas flow is manually controlled and locally monitored via a rotometer and a flow control valve. The sample flow is interrupted during the $\mathrm{GC}$ injection cycle by means of a solenoid control valve. The GC (GC-060) used is a small dual column unit with thermal conductivity detectors (TCD). The two columns allow for a variety of gas specie analyses. A molecular sieve packed column is used specifically for hydrogen analysis.

A moisture membrane filter (FLT-060) allows a liquid free sample to be drawn through a branch off the main sample line down stream of the inlet filters. Maintenance isolation valves (SV-060, SV-068) are provided at the loop inlet and outlet respectively. The selection of sample or calibration gas is determined by two solenoid controlled 3-way sample valves (SOV-061, SOV-062) in conjunction with the calibration gas isolation solenoid controlled valves (SOV-063, SOV-064) respectively. Another solenoid controlled 
3-way sample valve (SOV-060) is operated by the GC to allow the sampled gas to reach atmospheric pressure prior to column injection. The sample flow rotameter (FI-060) and flow control valve (SV-067) provide flow monitoring and control.

A moisture membrane filter (FLT-060) with a bypass flow is installed on the main sample line down stream from the inlet filters. It is used to provide a dry analysis sample from the main flow loop through a reducer to a $1 / 8$ " line for the GC. The GC sample flow of $5-10 \mathrm{cc} / \mathrm{min}$ is $1-2 \%$ of the main sample flow.

The flow goes through a solenoid controlled 3-way valve (SOV-061, SOV-062) then through a reducer to a $1 / 16$ " line which goes into either the 'A' Sample inlet or the 'B' Sample inlet on a Dual Column Gas Chromatograph (GC-060). The sample flow is passed through the GC and exits through a solenoid controlled 3-way valve (SOV-060) to a sample return line. The sample is provided with flow indication (FI-060) and control (SV-067) and merges with the main sample loop previous to the sample pump. Isolation valves (SV-060) and (SV-068) are provided for the GC flow loop for maintenance or when the GC flow loop is not utilized.

\subsubsection{Calibration Gas System}

Cylinders containing standard gasses are installed in the SHMS-E to support calibration and maintenance tasks of the electrochemical monitors as well as analytical equipment (the ammonia monitor and the gas chromatograph) when installed. The cylinders are placed in a gas bottle rack on the enclosure pad. A zero gas mixture of nominally $100 \mathrm{ppm}$ hydrogen and balance air is used to adjust the low end of the $\% \mathrm{H}_{2}$ sensors and to calibrate the GC when installed. The span gas mixture of nominally $5.0 \%$ hydrogen mixed with balance nitrogen is used for the top end adjustment of the $\% \mathrm{H}_{2}$ sensors.

A bottle of pre-purified $99.997 \%$ nitrogen and a bottle of pre-purified $99.997 \%$ helium are used for the GC carrier gasses. An calibration standard of nominally $100 \mathrm{ppm}$ Ammonia and balance air is used for the B\&K multi-gas analyzer, and a calibration standard of nominally $150 \mathrm{ppm}$ nitrous oxide $200 \mathrm{ppm}$ methane and balance air is available for the PORA plot Q column in the GC.

The calibration procedure for the electrochemical cells is contained in 6-TF-440. This procedure is implemented through manually operated local valves (SV-018, SV-019, SV034, SV-031 and SV-033). The electrochemical monitor "Zero" gas is also used as one of the GC calibration gasses.

The GC column 'A' calibration line can be isolated using manually operated local valve (SV-034) which is normally open. The GC column 'B' calibration line can be isolated using manually operated local valve (SV-036) which is normally open. The calibration functions for the gas chromatograph are automatically implemented through solenoid controlled valves (SOV-061, SOV-062, SOV-063, SOV-064). The manually operated local isolation valves (SV-032, SV-035) control the GC carrier gas and are normally open.

The multi-gas analyzer calibration line can be isolated using manually operated local valve (SV-072) which is normally open. The calibration functions for the multi-gas analyzer are 
automatically implemented through a solenoid controlled 3-way sample valve (SOV-071) in conjunction with a calibration gas isolation solenoid controlled valve (SOV-073).

The flow indicator with integral flow control valve (FIV-056) is included to ensure the proper flow rate to the hydrogen sensors. The pressure gauges and low pressure regulators (PCV/PI-035, PCV/PI-036, PCV/PI-055, PCV/PI-054, PCV/PI-056, PCV/PI072) are included to assure the proper supply pressure. A 15 micron filter (FLT-037, FLT-055, FLT-073) filters the outside air when purging the calibration gas manifold.

A pressure indicating transmitter (PDIT-060) with manually operated control valves (SV054, SV-055, SV-063, SV-064, SV-065, SV-066, and SV-070) is provided for verifying calibration gas pressures to the hydrogen sensors (NE-054/055), the gas chromatograph (GC-060), and the multi-gas analyzer (NIT-052).

\subsubsection{Alarm and Annunciator System}

The design of the SHMS-E alarm and annunciation system provides system outputs based on system inputs. Table 1.0 lists the system inputs and their respective outputs. An output can be a control function, alarm, or information light.

The design philosophy for the system was that each input must be able to trigger multiple outputs. The device inputs activate the outputs on loss of power (fail safe condition). The remote alarms are also designed for fail safe operation. Furthermore, the alarm beacons, remote alarms, and horn will automatically reset on loss of alarm condition. However, the remaining outputs will retain their alarm state on loss of alarm condition until manually reset. During alarm conditions, the operator can silence the horn without disabling the ability for another system input to activate the horn. Also, an alarm test function to test the alarm outputs was also included.

This design philosophy was implemented by the control logic used in the PLC and by using active inputs to the PLC for normal conditions. The PLC is responsible for processing the inputs and triggering the appropriate outputs for local or remote annunciation. Refer to drawing H-14-100836, Standard-E Hydrogen Monitoring System One-Line \& Elementary Diagrams for the following discussion.

The inputs to the PLC are designed to activate the annunciators on loss of power (fail safe condition), with the exception of the data recorder high hydrogen contacts. Loss of power to the hydrogen indicating transmitters (NIT-054/055) and the data recorder will not produce a "false positive", i.e. a high hydrogen alarm will not be generated. Loss of power to the PLC will activate the remote annunciators and the local beacons. On loss of incoming power to the entire system, the remote alarm contacts (which are also designed for fail-safe operation) will open, generating a remote alarm if the system has been connected to a remote monitor. 
Table 1.0 SHMS-E System Inputs and Outputs

\begin{tabular}{|c|c|}
\hline SYSTEM INPUTS & SYSTEM OUTPUTS \\
\hline Horn acknowledge & $\begin{array}{l}\text { Silences horn } \\
\text { (Indicating Tamps showing the cause of the alarm condition are not } \\
\text { affected) }\end{array}$ \\
\hline Sample flow low & $\begin{array}{l}\text { Trouble beacon } \\
\text { Trouble remote alarm } \\
\text { Horn } \\
\text { Sample flow low lamp }\end{array}$ \\
\hline $\mathrm{Hi} /$ Lo cabinet temp. & $\begin{array}{l}\text { Trouble beacon } \\
\text { Trouble remote alarm } \\
\text { Horn } \\
\text { Cabinet temp. hi/low lamp }\end{array}$ \\
\hline Alarm test & $\begin{array}{l}\text { Trouble beacon } \\
\text { Trouble remote alarm } \\
\text { High hydrogen beacon } \\
\text { High hydrogen remote alarm } \\
\text { Horn indicating lamps with the exception of Hydrogen Monitor Cal and } \\
\text { (A1] indicab Sample Lamps) }\end{array}$ \\
\hline Alarm reset & $\begin{array}{l}\text { Allows resetting of indicating lamps if the alarm condition has } \\
\text { previous }{ }^{2} \text { cleared: (wil not effect Reset Sampler. Hydrogen Monitor } \\
\text { Cal and Grab Sample Lamps) }\end{array}$ \\
\hline $\begin{array}{l}\text { High range high } \\
\text { hydrogen }\end{array}$ & $\begin{array}{l}\text { High hydrogen beacon } \\
\text { High hydrogen remote alarm } \\
\text { Horn hydrogen lamp } \\
\text { High hy } \\
\text { Grab sample solenoid } \\
\text { Grab sample lamp } \\
\text { Reset sampler lamp }\end{array}$ \\
\hline $\begin{array}{l}\text { Low range high } \\
\text { hydrogen }\end{array}$ & $\begin{array}{l}\text { High hydrogen beacon } \\
\text { High hydrogen remote alarm } \\
\text { Horn hydrogen lamp } \\
\text { High hyd } \\
\text { Grab sample solenoid } \\
\text { Grab sample lamp } \\
\text { Reset sampler lamp } \\
\end{array}$ \\
\hline $\begin{array}{l}\text { Low calibration gas } \\
\text { temp. }\end{array}$ & $\begin{array}{l}\text { Trouble beacon } \\
\text { Trouble remote alarm } \\
\text { Horn } \\
\text { Gas temp low lamp }\end{array}$ \\
\hline Low sample gas temp. & $\begin{array}{l}\text { Trouble beacon } \\
\text { Trouble remote alarm } \\
\text { Horn } \\
\text { Gas temp low lamp }\end{array}$ \\
\hline Reset sampler & $\begin{array}{l}\text { Resets the following: } \\
\text { Grab sample solenoid valves } \\
\text { Grab sample lamp } \\
\text { Reset sampler lamp }\end{array}$ \\
\hline Grab sample & $\begin{array}{l}\text { (These output occurs for five minutes) } \\
\text { Grab sample solenoid valves } \\
\text { Grab sample lamp } \\
\text { (This output is locked in until reset) } \\
\text { Reset sampler lamp }\end{array}$ \\
\hline
\end{tabular}


The high hydrogen (red) beacon, the trouble (amber) beacon, the remote alarms, and the audible wavering horn automatically reset on loss of the alarm condition. Conversely, the enclosure alarm indicator lamps maintain their alarm state after the loss of the alarm condition, until manually reset. The enclosure alarm indicator lamps are turned on directly by a PLC output. Conversely, on a high hydrogen alarm condition the PLC deenergizes a high hydrogen relay (CR-055) to provide an open contact to a remote annunciator interface (TB-2) and to turn on the high hydrogen beacon. On any other alarm conditions, the PLC de-energizes an enclosure trouble relay (CR-063) to turn on the trouble beacon and to provide an open contact to a remote annunciator interface (TB-2).

The enclosure alarm annunciator horn is activated with each alarm. The HORN ACKNOWLEDGE push button (PB-050) allows the operator to disable the horn during an alarm condition without disabling the ability for another system input to activate the horn.

The ALARM RESET push button (PB-051) clears all local alarm annunciator lamps, if the alarm condition has returned to normal. For example, when a low gas temperature condition is reached the following occurs: The horn sounds, the trouble (amber) beacon is activated, the low gas temperature lamp is turned on and the remote enclosure trouble annunciator contacts open. An operator would be sent to investigate the problem. The operator would acknowledge the horn and proceed with troubleshooting. A few minutes later, a low hydrogen flow condition is reached. The horn sounds again, and now the low hydrogen flow enclosure lamp is turned on. After acknowledging the horn and correcting both problems, the trouble beacon and the remote enclosure trouble annunciator automatically reset. The operator then pushes the ALARM RESET button, to reset the gas temperature low and low hydrogen flow lamps.

The two beacons, horn, remote annunciation, and all enclosure lamps with the exception of the Grab Sample and Reset Sampler can be tested at the same time with the ALARM TEST (PB-052) push button provided on the enclosure door. Consequently, the programmable logic controller output drivers are also verified with this test.

The grab sample system allows for both operator or automatic initiation of the grab sampler. When a high hydrogen event occurs or the GRAB SAMPLE push button (PB059 ) is depressed, a grab sample is initiated. The grab sample will sample for five minutes. Subsequent high hydrogen events or operator initiated grab samples will not retrigger the sampler until the system is manually reset. The RESET SAMPLER (PB058) push button restores the capability of operator-initiated or automatic grab sampling after it has been locked due to a prior grab sampling event.

\subsection{Enclosure Power Distribution}

A/C Power distribution for the sample pump, heater/air conditioner, heat trace, enclosure instrumentation, and a maintenance equipment outlet is via a 240/120 VAC enclosure feed. The power source for each enclosure is listed in Tank farms Plant Operating Procedure TO040-041. The power needs for the Standard-E Hydrogen Monitoring System are nominally: $240 \mathrm{VAC}$ at 9 Amps and $120 \mathrm{VAC}$ at $15 \mathrm{Amps}$. Refer to Drawing H-14-100836 for the following:

The sample pump requires $240 \mathrm{VAC}$ at 4 Amps with overcurrent protection provided via a two pole 15 Amp circuit breaker (CB-3\&4). 
The heater/air conditioner unit (ACU-060) requires $240 \mathrm{VAC}$ at 5 Amps. A two pole 10 Amp circuit breaker (CB-1\&2) provides overcurrent protection.

Heat trace for the sample gas line (HT-050) and calibration gas line (HT-056) requires 120 $\mathrm{VAC}$ at 8.3 Amps. A single pole $15 \mathrm{Amp}$ circuit breaker (CB-5) provides overcurrent protection for both heat trace power circuits. The circuit breaker feeds a ground fault circuit interrupter (GFCI) for both heat trace circuits. A temperature controller energizes a solid state relay (JY-050 or JY-056) whenever the corresponding heat trace (HT-050 or HT-056) is needed. Gating on a zero fired triac circuit, effectively provides power to the heat trace.

An enclosure light (LT1) and a ground fault interrupting receptacle are included in the enclosure for maintenance purposes. An intermittent load of $3 \mathrm{amps}$ is anticipated for the receptacle. A single pole 15 Amp circuit breaker (CB-6) provides overcurrent protection for both. Light operation is via a hand switch (HS-1) with a single pole double throw contact.

All of the enclosure instruments require $120 \mathrm{VAC}$ at a maximum of 4 Amps. A single pole 10 Amp circuit breaker (CB-7) feeds a $750 \mathrm{VA}$ isolation transformer which provides power to the 120 VAC Instrument Line. The transformer is included to protect the instruments from power line noise due to electrical disturbances such as lightning, utility network switching and the operation of electric motors. Each instrument that is fed off of this $120 \mathrm{VAC}$ line is individually fused.

The 120 VAC Instrumentation Line also feeds a 24 VDC power supply. The Flow Indicating Transmitter (FIT-057), the GC differential pressure transmitter (PDIT-060), and the calibration gas control solenoid valves (SOV-061, SOV-062, SOV-063, SOV-064, SOV-071, SOV-073) require $24 \mathrm{VDC}$.

A Gas Sample Conditioner (GSC) may be included on the sample line for sample moisture separation. A single pole 15 Amp circuit breaker (CB-8) provides overcurrent protection.

\subsubsection{Heat Trace and Environmental Control}

Sample and calibration gas line temperature control is needed for two reasons. The first is to keep the sample gasses above the dew point, since they may contain a relatively high concentration of water vapor. The second is to ensure the required response time from the electrochemical hydrogen monitor.

A temperature control set point of $29.4^{\circ} \mathrm{C}\left(85^{\circ} \mathrm{F}\right)$ has been established as the design temperature for all gas sample lines. The value of $29.4^{\circ} \mathrm{C},\left(85^{\circ} \mathrm{F}\right)$ was established to provide a 5.4 degree $\mathrm{C}$ margin of error for the heat trace system above the worst case $23.9^{\circ} \mathrm{C}\left(75^{\circ} \mathrm{F}\right)$ dew point temperature (condensation temperature). The $23.9^{\circ} \mathrm{C}\left(75^{\circ} \mathrm{F}\right)$ temperature requirement was picked after reviewing wet/dry bulb temperatures taken for humidity measurements on the 101-SY exhaust header during a two year period. They showed a winter dew point of $14^{\circ} \mathrm{C}\left(57^{\circ} \mathrm{F}\right)$ and a summer dew point of $23.9^{\circ} \mathrm{C},\left(75^{\circ} \mathrm{F}\right)$. Preventing condensation is important to achieving measurement accuracy. Some gasses chemically react very quickly with water. If this reaction with water occurs in the sample lines then the gasses presented to the instruments are not the same as the gasses at the sample point. Heat trace is provided to prevent this measurement error. 
The second reason for heat trace is to provide the hydrogen sensors a gas sample between $24(75)$ and $49^{\circ} \mathrm{C}\left(120^{\circ} \mathrm{F}\right)$. The cell's response time to a step change in hydrogen increases as the sample temperature decreases below $21^{\circ} \mathrm{C}\left(70^{\circ} \mathrm{F}\right)$. Tests at $21^{\circ} \mathrm{C}\left(70^{\circ} \mathrm{F}\right)$ show a 120 second response to $90 \%$ of the final value for a step change in hydrogen. This response time shortens as the sample temperature increases to $21^{\circ} \mathrm{C}\left(120^{\circ} \mathrm{F}\right)$ where sample stream humidity then start to increase response time. Measurements of tank exhaust temperatures in $241-\mathrm{SY}-101$ have been as low as $4^{\circ} \mathrm{C}\left(40^{\circ} \mathrm{F}\right)$ when the average daily January ambient temperature was around $-18^{\circ} \mathrm{C}\left(0^{\circ} \mathrm{F}\right)$. The heat trace system is needed to raise the temperature of the winter gas samples to $27^{\circ} \mathrm{C}\left(80^{\circ} \mathrm{F}\right)$ before the gas sample enters the enclosure. The calibration gas lines, in addition to the sample gas lines are heat traced due to the outdoor location of the calibration gas bottles.

Enclosure temperature control is needed for two reasons. The first is to maintain the sample and calibration gasses that have been heat traced at a minimum of $21^{\circ} \mathrm{C}\left(70^{\circ} \mathrm{F}\right)$ during the winter. The second reason is to maintain the instruments in their optimal operating temperature ranges which is usually above $16^{\circ} \mathrm{C}\left(60^{\circ} \mathrm{F}\right)$ but below $32^{\circ} \mathrm{C}\left(90^{\circ} \mathrm{F}\right)$.

\subsection{OPERATING PROCEDURES}

Tank Farms Operating Procedure TO-040-041 is the main source document for operating the SHMS-E Enclosure. The analytical monitoring equipment of the $\mathrm{GC}$ and its support systems will be managed by engineering through informal desk instructions. The following is a listing of the various operating, troubleshooting, and emergency responses contained in the procedure:

SHMS INITIAL STARTUP

OPERATING PROCEDURES

SHMS SHUTDOWN

PERFORM SHMS GRAB SAMPLE

ISOLATE SHMS CABINET

RESTART SHMS CABINET FROM ISOLATION

GAS SAMPLE TRANSPORT

SHMS OPERATOR ROUTINES

PERFORM DAILY SHMS SURVEILLANCE

SHMS TROUBLESHOOTING

TROUBLESHOOT SHMS TEMPERATURE SYSTEM

TROUBLESHOOT SHMS MAIN SAMPLE LOOP

EMERGENCY RESPONSE

RESPOND TO SHMS HIGH HYDROGEN STROBE LIGHT

ALARM RESPONSE

RESPOND TO SHMS TROUBLE STROBE LIGHT

RESPOND TO SHMS LOCAL PANEL ALARM LAMPS

RESPOND TO LOW HYDROGEN FLOW ALARM

RESPOND TO GAS TEMP LOW ALARM

RESPOND TO CABINET TEMP ALARM

RESPOND TO HIGH HYDROGEN PANEL LAMP 
Tank Farms Operating Procedure TO-040-043 is the document for operating the SHMS-C Gas Sample Conditioner when installed.

\section{OPERATING PROCEDURES}

GAS SAMPLE CONDITIONER (If Installed)

The following procedures are not required during normal operation, but are used during the initial start up or calibration of the system.

\subsection{Perform Initial Instrument Programming}

Note - This is done prior to field/facility calibration and operation.

6.1.1 PROGRAM the Newport Digital Voltmeter used as the Indicating Transmitter for the Whittaker Percent Hydrogen Monitor (NIT-054/055) per CVI 22192 Supplement 22 and the configuration list in Appendix A.

6.1.2 PROGRAM the Westronic 3 Data Recorder (NR-054) used in the SHMS-E per CVI 22192 and the configuration list in Appendix A.

6.1.3 PROGRAM the Programmable Logic Controller (YYC-001) per CVI 22192; HNF-SD-WM-CSDD-021, SHMS-E PLC Computer Software Design Description; and H-14-100843, Standard E Hydrogen Monitoring System P.L.C. Ladder Diagram.

6.1.4 PROGRAM the Temperature Indicator (TIS-062) and the Temperature Indicating Controllers (TIC-050/056) per CV1 22192 Supplement 19 and the configuration list in Appendix A.

6.1.5 PROGRAM the Low flow alarm module (FSL-057) per Appendix A.

\footnotetext{
Tewport is a trademark of Newport.

${ }^{2}$ Whittaker is a trademark of the Whittaker corporation.

3 Westronics is a trademark of Westronics, Inc.
} 


\subsection{SCHEDULED MAINTENANCE}

\subsection{Instrument Calibration Procedures}

\subsubsection{Whittaker Percent Hydrogen Monitor}

Calibrate the Whittaker Hydrogen Monitor (NIT-054/055) per 6-TF-440 every 3 months.

\subsubsection{Data Recorder (SHMS-E)}

Calibrate the Data Recorder (NR-054) per 6-TF-175 every 12 months.

\subsubsection{Sample System Pressure Indicator}

Calibrate the Main Sample Loop Pressure Indicator (PI-053) per 6-TF-509 every 12 months.

\subsubsection{Filter Differential Pressure Indicator}

Calibrate the Filter Differential Pressure Indicator (PDI-051) per 6-TF-509 every 12 months.

\subsubsection{Main Sample Loop Flow Transmitter}

Calibrate the Main Sample Loop Flow Transmitter (FIT-057) per 6-TF-259 every 12 months.

\subsubsection{Calibration Loop Pressure Transmitter}

Calibrate the Calibration Loop Pressure Transmitter (PDIT-060) per 6-TF-259 every 12 months.

\subsubsection{Multi-gas Analyzer}

If installed, calibrate the B\&K multi-gas analyzer (NIT-052) per 6-TF-143 every 12 months.

\subsubsection{Gas Chromatograph Columns}

Routinely, as necessary, Bake Out the GC columns and re-establish proper analytical methods files. 


\subsection{GUIDE TO TROUBLE SHOOTING}

The warning and indicating lights on the front of the SHMS-E enclosure provide information on the status of the system. The following is a discussion of various troubleshooting methods that could be applied to diagnose a problem with the system.

\subsection{Cabinet Temperature}

The cabinet temperature trouble light will illuminate when the enclosure temperature exceeds the high limit or falls below the low limit. Items to check when this occurs would include the operation and set point of the heater and air conditioner unit, firmness of the door seal with the enclosure, and last, the actual alarm set points of the temperature monitor module.

Since the high and low temperature alarm functions are combined in a single light it may be difficult to determine which condition caused the problem if it is sporadic in nature. A portable battery operated temperature recorder can be used in the enclosure for a time history of enclosure temperature.

If adjustments are made to the thermostats' set points, remember that the enclosure temperature will not change instantaneously. There will be a time delay for the temperatures to stabilize. Make all set point changes in small increments and wait for the system to respond following the adjustment. Also if the temperature outside the enclosure is extreme, try to minimize the length of time the door is open. This will reduce the stabilization time.

\subsection{High Hydrogen}

A high hydrogen warning should not be disregarded as an instrument failure. If it occurs, follow the appropriate high hydrogen response. If it can be independently shown later on that the instrument is malfunctioning the following steps can be used as an aid in troubleshooting the system.

The Infinity ${ }^{4}$ NIT-054/055 displays should match the data recorders digital display channel 1 to within $+/-0.010$ and channel 2 to within $+/-.005$. During operation, the Whittaker cells should track one another and read approximately the same number. Refer to the traces to determine if they are tracking.

To verify that a cell is responding, inject the high level calibration gas and observe the cells response on its associated infinity readout. Finally, check the data recorders alarm relay set points. Ensure they are set to the value listed in appendix B.

\subsection{Low Hydrogen Flow}

Check the pump and ensure that it is running. If not, check the status of CB-3, it may have tripped. After checking the pump, perform a valve line up per TO-040-041 to ensure that the system has been placed in operation properly. Note if any of the valves are found out of their normal position.

Next check the filter differential pressure and the system pressure gauges. If the differential pressure gauge is off scale high and the system pressure gauge is indicating $<-10^{\prime \prime} \mathrm{Hg}$, the

4 Infinity is a trademark of Newport. 
filters are clogged and need to be replaced. If the system pressure is high, $>-1^{\prime \prime} \mathrm{Hg}$, there may be a break in the system or a mechanical problem with the vacuum pump.

Check the digital display of the flow indicator. It should indicate the current pressure drop across the laminar flow element. The digital display should change in response to changes in the position of the flow control valve. Next check the calibration of the flow alarm module by performing 6 -TF-259. If the flow alarm module cannot be calibrated then the transmitter/alarm module are suspect.

\subsection{Gas Temp Low}

The gas temp low trouble light will illuminate when either the sample or calibration gas temperature falls below the low limit set point. Items to check when this occurs would include the set point of the heat trace unit. Next, check the mechanical condition of the heat trace, thermocouple and associated insulation. They all need to be in close proximity to the heat traced line. Next, adjust the controller set point temperature above ambient and monitor the sensed temperature. If it does not increase, the problem is in the heat trace system and not in the sensing system.

Since both the sample and calibration gas low temperature alarm functions are combined in a single light it may be difficult to determine which system caused the problem if it is sporadic in nature. Possible solutions for this could include use of a portable battery operated temperature recorder that is coupled to the heat trace thermocouple.

\subsection{Programmable Logic Controller}

The PLC does not have an enclosure mounted door warning lamp, but it does have several LEDs on its front cover which can be a valuable diagnostic tool when problems occur. Prior to looking at the PLC, complete the applicable section for the respective warning /trouble light, then proceed as follows. Ensure that the POWER OK light is illuminated.

If an alarm or warning condition is being displayed but the respective system parameter is normal, such as a low gas temperature on a $100^{\circ}$ day, check the PLCs input status LEDs. The inputs were designed to be fail safe. What this means is that under normal conditions the input monitoring LEDs for the active channels would all be on. If one of these LEDs is off, there is an electrical problem between the item producing the alarm or trouble signal and the PLC. 


\subsection{REFERENCES}

WHC-SD-WM-SDD-077, Standard-E Hydrogen Monitoring System, System Design Description, (Schneider)

HNF-SD-WM-CSDD-021,

H-14-100835,

H-14-100836,

H-14-100837,

H-14-100838,

H-14-100839,

H-14-100840,

H-14-100841,

H-14-100842,

H-14-100843,

H-14-100844,

H-14-100845,

H-14-100846,

H-14-100847,

CVI 22129

CVI 22192
SHMS-E PLC Computer Software Design Description,(Ermi)

Standard E Hydrogen Monitoring System Piping \& Instrumentation Diagram

Standard E Hydrogen Monitoring System One Line, Elementary Diagram.

Standard E Hydrogen Monitoring System Cabinet Assembly.

Standard E Hydrogen Monitoring System Wiring Diagram.

Standard E Hydrogen Monitoring System Loop Diagrams.

Standard E Hydrogen Monitoring System Interior Panels \& Brackets.

Standard E Hydrogen Monitoring System Instrument Panel Assembly.

Standard E Hydrogen Monitoring System Cabinet Modifications.

Standard E Hydrogen Monitoring System P.L.C. Ladder Diagram.

Standard E Hydrogen Monitoring System Equipment Arrangement.

Standard E Hydrogen Monitoring System Sample Pump Stand Assembly.

Standard E Hydrogen Monitoring System Mult-Gas Analyzer Mod. Standard E Hydrogen Monitoring System I/O Tray/Drawer Assembly. 
HNF-SD-WM-OMM-029, REV, 0

PAGE 20 OF 37

\section{APPENDIX A}

CONFIGURATION OF PROGRAMMABLE INSTRUMENTS 


\section{LISTING OF NIT-054/055 INITIAL SETUP CONFIGURATION}

Verify the proper jumper selection for the $0-100 \mathrm{mV}$ range and FAST SCAN rate (S1A, S2A, S2F, and S2M)

The initial condition is to UNLOCK access to all the applicable program functions. Using the guidance of the Newport Infinity operations manual and the front panel pushbuttons, verify the setting of the following configuration:

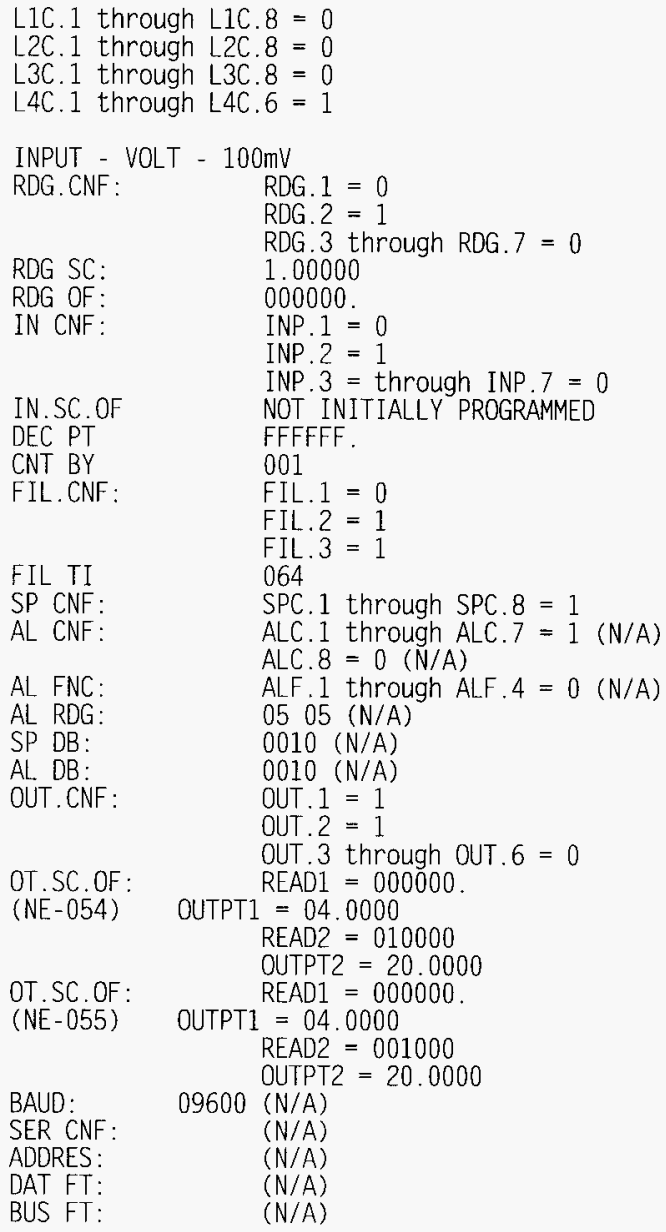


SERCNT:

$(\mathrm{N} / \mathrm{A})$

At the completion of the initial settings LOCKOUT the unused functions with the following settings:

L1C. 1 through L1C.8 = 1 L.2C. 1 through L2C. $3=1$ L2C. 4 through L2C. $6=0$ L2C. 7 through L2C. $8=1$ L3C. 1 through $L 3 C .7=1$

L3C. $8=0$

L4C. 1 through $L 4 C .6=1$ 
LISTING OF NR-054 INITIAL SETUP CONFIGURATION

SHMSREC?

WESTRONIC SMARTVIEW DATA RECORDER

Program Parameters (version 1.23)

Press MENU

Press

PROG NOTE: New program parameters must be saved to nonvolatile memory using the Learn option.

Time \& Date ENTER

??:??:??

(24 hour format) \& (Month/day/year format)

YES

NO

hours? $\rightarrow$ ? $\leftarrow$ ENTER

minutes? $\rightarrow$ ? ? $\leftarrow$ ENTER

??/??/??

YES

seconds? $\rightarrow$ ?? $\leftarrow$ ENTER

NO

month? $\rightarrow$ ? $\leftarrow$ ENTER

day? $\rightarrow ? ? \leftarrow$ ENTER

year? $\rightarrow$ ? $\leftarrow$ ENTER

\section{Display ENTER}

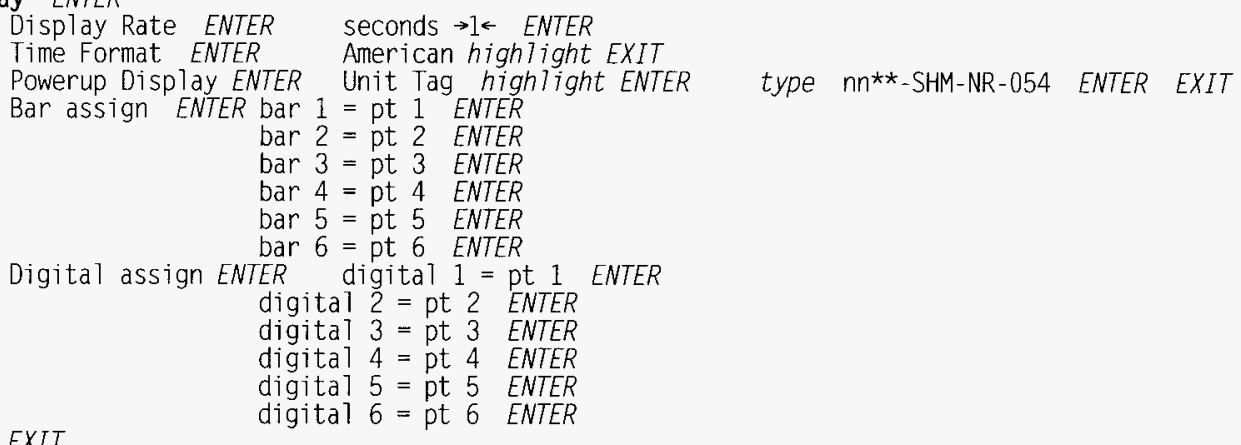


Chart/Pens ENTER

Speed ENTER

Repeat 3 times

1.

Scales ENTER

2.

Scales ENTER

3.

Scales ENTER

Pens ENTER

Direct

EXIT
Autospeed highlight ENTER autospd $=$ YES* YeS ENTER Setspeed highlight ENTER Tospd $=10.0$ ENTER $(\mathrm{in} / \mathrm{hr}$ )

\section{EXIT} hispd $=60.0$ ENTER

Scale? 1A ENTER Scale type ENTER LIN highlight EXIT Scale ends ENTER place? 3 ENTER

$$
10 \rightarrow-2.500 \text { ENTER }
$$$$
\text { mid } \rightarrow 3.750 \text { ENTER }
$$$$
h i \rightarrow 10.000 \text { ENTER }
$$

Scale grid ENTER major $\rightarrow 10 \leftarrow$ ENTER

minor $\rightarrow 5 \leftarrow$ ENTER

Scale units ENTER SPC (none) ENTER

Scale? $1 B$ ENTER Scale type ENTER LIN high7ight EXIT Scale ends ENTER place? 3 ENTER

$$
\begin{array}{ll}
10 \rightarrow-0.250 & \text { ENTER } \\
\text { mid } \rightarrow 0.375 & \text { ENTER }
\end{array}
$$

Scale grid ENTER major $\rightarrow 10 \leftarrow$ ENTER

minor $\rightarrow 5 \leftarrow$ ENTER

$$
\text { Scale units ENTER SPC (none) ENTER }
$$

Scale? 1C ENTER Scale type ENTER LIN high7ight EXIT Scale ends ENTER place? 3 ENTER

$$
\begin{aligned}
& 10 \rightarrow 0.000 \text { ENTER } \\
& \operatorname{mid} \rightarrow 5.000 \text { ENTER }
\end{aligned}
$$

Scale grid ENTER major $\rightarrow 10 \leftarrow$ ENTER

minor $\rightarrow 5 \leftarrow$ ENTER

Scale units ENTER SPC (none) ENTER EXIT

pen $3=$ pt 3 ENTER

pen $4=$ pt 4 ENTER

pen $5=$ pt 5 ENTER

pen $6=$ pt 6 ENTER

EXIT 


\section{Points ENTER}

Prog point highlight ENTER

Repeat 3 times

1 . point? 1 ENTER modify pt ENTER

linear ENTER
10V ENTER point tag ENTER

Input scāle ENTER

$10 \rightarrow 0.000$ ENTER

hi $\rightarrow 5.000$ ENTER

Output scale ENTER

places? 3 ENTER

$10 \rightarrow-2.500$ ENTER

hi $\rightarrow 10.000$ ENTER

Currents ENTER

Current $=N 0^{*}$ ENTER

Filter ENTER

seconds $\rightarrow 0 \leftarrow$ ENTER

Eng units ENTER

units $\rightarrow \% \mathrm{H} 2<$ ENTER

Alarms ENTER

A7m Timits ENTER

alarm \#? 1 ENTER

Type = high ENTER

ENTER high $\rightarrow 0.625 \leftarrow$

contact \#? 1

ENTER EXIT

Alm deadband ENTER

$\mathrm{db} \rightarrow 0.000 \leftarrow$ ENTER

Alm delay ENTER

seconds $\rightarrow 0 \leftarrow$ ENTER EXIT

Chart Scale ENTER EXIT 
10V ENTER point tag ENTER

NE 55 ENTER
Input scăle ENTER

$10 \rightarrow 0.000$ ENTER

hi $\rightarrow 5.000$ ENTER

Output scale ENTER

places? 3 ENTER

$10 \rightarrow-0.250$ ENTER

hi $\rightarrow 1.000$ ENTER

Currents ENTER

Current $=$ NO* ENTER

Filter ENTER

seconds $\rightarrow 0 \leftarrow$ ENTER

Eng units ENTER

units $\rightarrow$ \% 2 2 $\leftarrow$ ENTER

Alarms ENTER

Alm 7 imits ENTER

a)arm \#? 1 ENTER

Type $=$ high ENTER

ENTER

high $\rightarrow 0.625 \leftarrow$

contact \#? 1

ENTER EXIT

Alm deadband ENTER

$\mathrm{db} \rightarrow 0.000 \leftarrow$ ENTER

Alm delay ENTER

seconds $\rightarrow 0-$ ENTER EXIT

Chart Scale ENTER EXIT

chartsc $1=\mathrm{B} \quad$ ENTER 
10V ENTER point tag ENTER

Input scale ENTER

$10 \rightarrow 0.000$ ENTER

hi $\rightarrow 10.000$ ENTER

Output scale ENTER

places? 3 ENTER

$10 \rightarrow 0.000$ ENTER

hi $\rightarrow 10.000$ ENTER

Currents ENTER

Current $=N^{*} \quad$ ENTER

Filter ENTER

$$
\text { seconds } \rightarrow 0 \leftarrow \text { ENTER }
$$

Eng units ENTER

units $\rightarrow$ VOLTS $\leftarrow$ ENTER

ATarms ENTER

Alm Timits ENTER

alarm \#? 1 ENTER EXIT

Type = none ENTER

Alm deadband ENTER

$\mathrm{db} \rightarrow 0.000 \leftarrow$ ENTER

Alm delay ENTER

seconds $\rightarrow 0 \leftarrow$ ENTER

EXIT

Chart Scale ENTER

chartscl $=C$ ENTER EXIT 


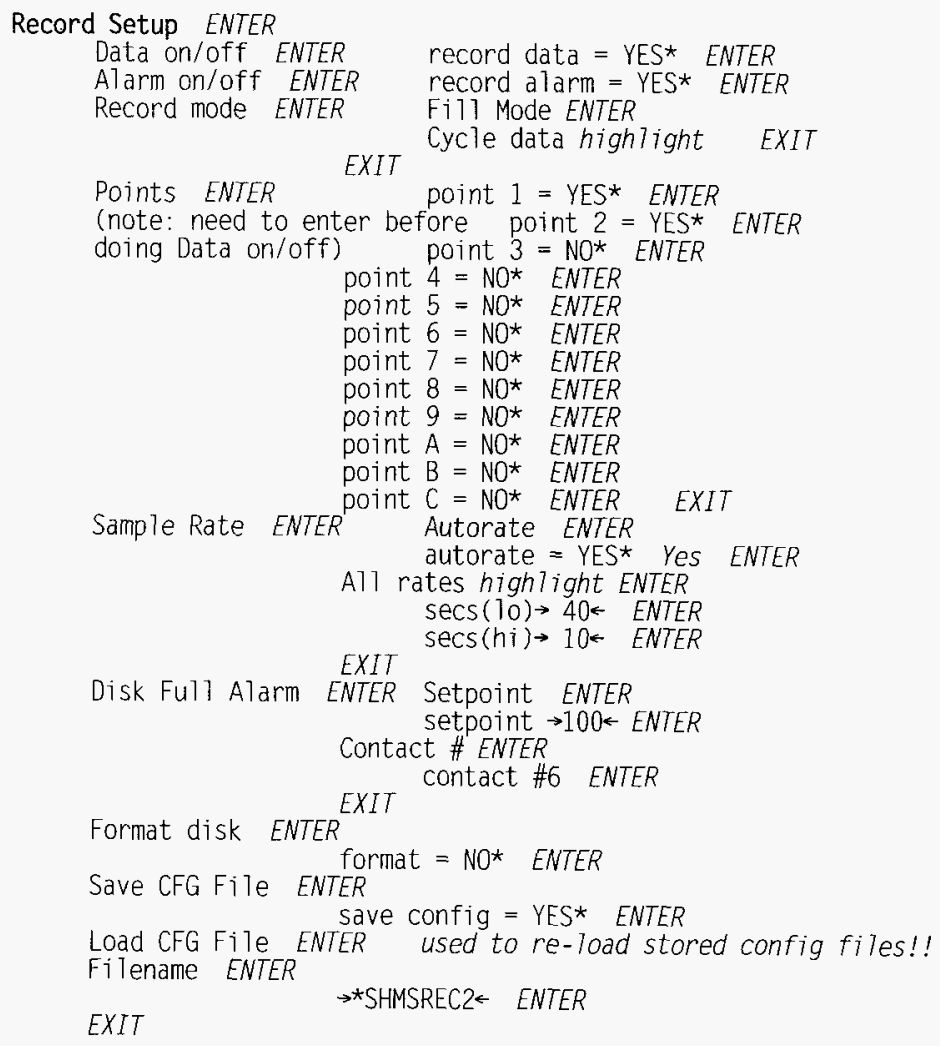


Measurement ENTER

ADC control ENTER (CAUTION - directly affects measurements)

Cal Adc ENTER

cal scales ENTER

scale $105 \mathrm{mV}$ ENTER
cal input? 1 ENTER

Cal currents ENTER

cal input? 1 ENTER

ETC.

Tcbo interval ENTER

frequency ENTER

Span\&offset ENTER

seconds $\rightarrow 300 \leftarrow$ ENTER

Demo Mode ENTER

spnofs $=$ NO ${ }^{\star}$ ENTER

Demo mode $=$ NO* ENTER

Digital I/O ENTER

Contact outs ENTER

$$
\begin{aligned}
& \text { Alarms clear ENTER } \\
& \text { opn clr }=\text { YES* } \\
& \text { ACKTER } \\
& \text { key ENTER } \\
& \text { opn cck }=\text { NO* ENTER } \\
& \text { Failsafe ENTER } \\
& \text { flsafe }=\text { NO* ENTER } \\
& \text { Reflash ENTER } \\
& \text { reflash }=N^{*} \text { ENTER } \\
& \text { EXIT }
\end{aligned}
$$

Switches in (not used)

Event msgs (not used) 
Com ports ENTER

Com Port ENTER

Protocol ENTER

Modbus rtu highlight ENIER

Port setup ENTER

9600 baud highlight ENTER parity? N ENTER

EXIT stopbits? 1 ENTER

Network ID ENTER

net id $\rightarrow 1$ ENTER

EXIT

Network ID ENTER

Modem Setup ENTER

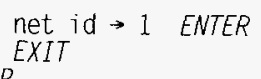

net id $\rightarrow 1$ ENTER

modem enab7e ENTER

EXIT modem $=N 0^{\star} \quad$ ENTER

EXIT

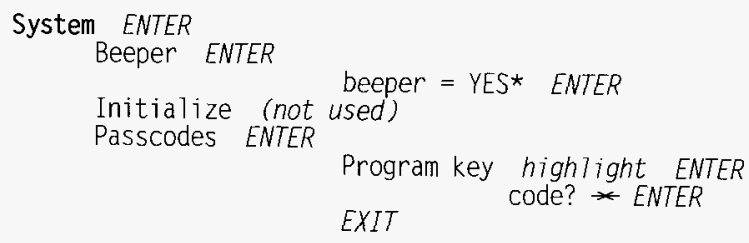

Learn ENTER (Stores new parameters) 


\section{TEMPERATURE CONTROLLER INITIAL CONFIGURATION}

The Sample and Calibration Gas Heat Trace temperature controllers. TIC-050/056, operate identically by driving a solid state zero crossing relay which in turn provides the heat trace heater with $120 \mathrm{Vac}$ power. Set point 2 (SP2) of the temperature controllers provides the process alarm. The enclosure temperature indicator and alarm. TIS-062, provides no control function, but indicates the enclosure temperature and alarms high (SP1) and low (SP2) temperature conditions. The temperature controllers are primarily configured with factory default settings. Special configuration settings will be discussed below. The configuration of the controllers is accomplished through the front panel pushbuttons. The function of each button is as follows:

p Selects Set-Up Mode which provides entry into Function and Option (F/0) selection. Refer to Operator's Manual for F/O descriptions.

* Displays main (SP1) set point temperature.

* Keyed together increases main set point temperature.

* Keyed together decreases main set point temperature.

av When in the Set-Up Mode, indexes FUNCTION/OPTION number up or down in single digits.

* When in Set-Up Mode, changes manipulation from FUNCTIONS to OPTIONS and vice versa.

NOTE: The temperature controller set point 2 (SP2) is configured in the Set-Up Mode as Function 2.

The initial configuration sets the controllers to operate with a type $K$ thermocouple input, sets the indicator to display in ${ }^{\circ} \mathrm{F}$. limits the set point control range to between 32 and $150^{\circ} \mathrm{F}$, and adjusts the alarm set points to an initial value. Verify that the following FUNCTIONS/OPTIONS have been selected for each of the controllers/indicators: 
HNF-SD-WM-OMM-029, REV. 0

PAGE 32 OF 37

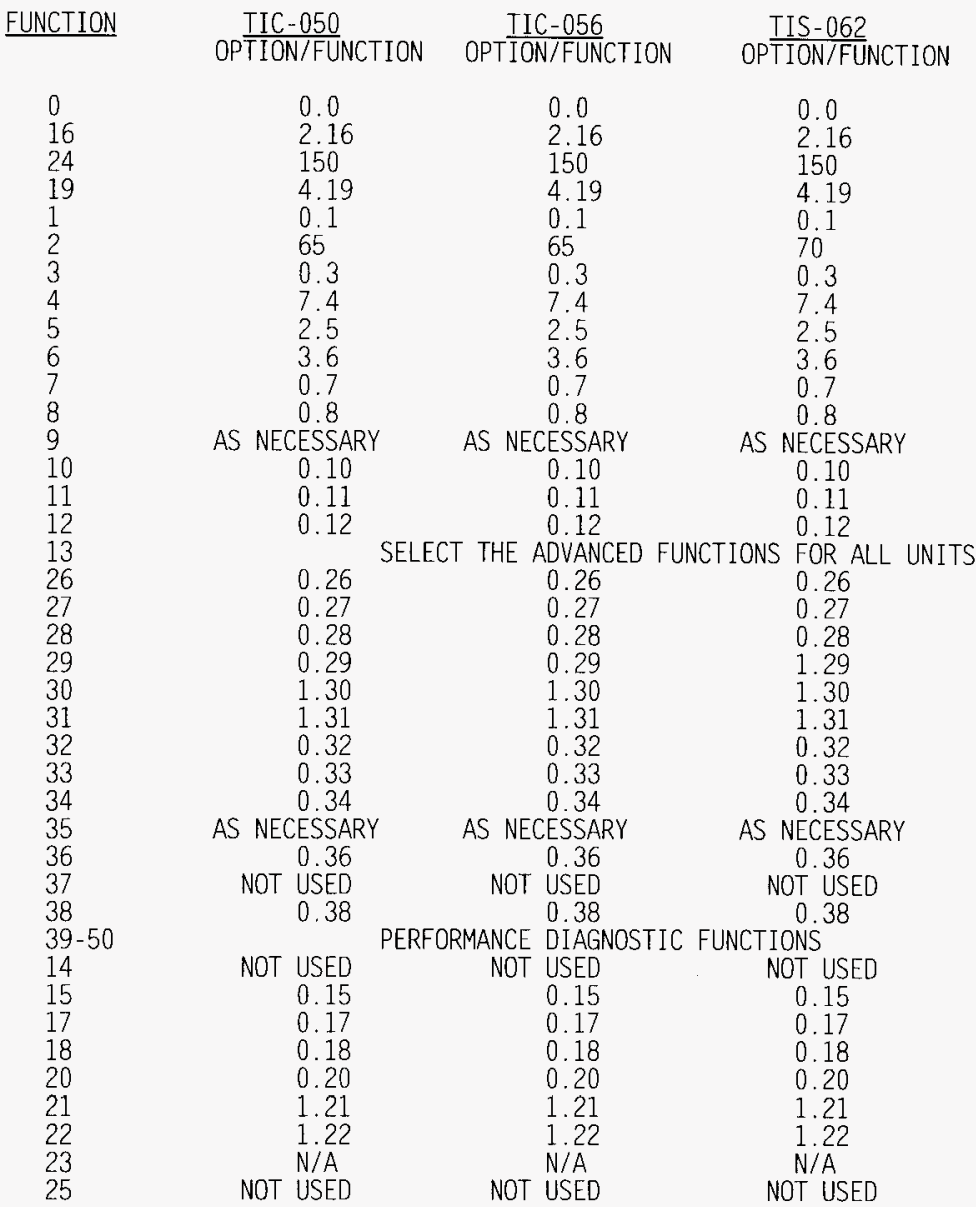

To operate the individual temperature controllers simply CLOSE the associated fused switches and breakers, and adjust the set points to achieve the temperature desired. If the controllers are unstable and will not control to the desired set point, special tuning parameters may be implemented to establish proper control characteristics. 
Setting the Main Sample Loop Low Flow Alarm

NOTE - The setting of the main loop flow alarm set point will be performed in conjunction with the setting of the main loop flow. Once the system dynamic pressures have been established it will be relatively easy to adjust the flow with the FCV to obtain the low flow value with one or two iterations. Once the low flow alarm value is established. the trip can be easily set and verified with the flow adjustment of the FCV.

10.0 VERIFY that the alarm module (FAL-057) configuration is as follows:

10.1 ENSURE that the input jumper $W 2$ is in the I position.

10.2 ENSURE that the INPUT RANGE DIP switch SW1 positions are selected for $20 \mathrm{~mA}$ as fOllows: 1-OFF, 2-ON. 3-ON. 4-OFF.

10.3 ENSURE that the OUTPUT RANGE DIP switch SW2 positions are selected as follows: 1-ON, 2-OFF, 3-OFF, 4-OFF, 5-OFF, 6-ON.

10.4 ENSURE that the DEADBAND potentiometer is adjusted to the minimum deadband, ful ly CCW.

10.5 ESTABLISH the main loop flow to $5.6 \pm 2.8$ SLM $(0.2 \pm 0.1$ SCFM $)$.

NOTE - Use the procedure in 6-TF-440 as a guide for establishing the main loop flow.

10.6 NOTE the system pressure PI-053 and the flow element differential pressure FIT-057.

10.7 VERIFY that the alarm is reset (TRIP LED is OFF).

10.8 ADJUST the SET POINT potentiometer until the alarm relay just trips. (NOTEIf the TRIP LED is ON. adjust the set point potentiometer CCW. If the TRIP LED is OFF, adjust the set point potentiometer CW. )

10.9 VERIFY that the red TRIP LED i1luminates.

10.10 INCREASE the flow by using SV-024 until the alarm is reset.

10.11 SLOWLY DECREASE the flow using SV-024 until the alarm is tripped.

10.12 VERIFY that the alarm trips at $5.6 \pm 2.8$ SLM $(0.2 \pm 0.1$ SCFM $)$.

10.13 REPEAT steps 10.5 through 10.12 as necessary unti 1 the alarm trips at the desired flow.

10.14 SET the low flow alarm trip deadband.

10.14.1 ADJUST the DEADBAND potentiometer fully $\mathrm{CW}$ for $100 \%$ deadband.

10.14.2 VERIFY the main loop flow and low flow set point are adjusted to low flow values. 
10.14.3 INCREASE the flow using SV-024 until the FE differential pressure indicates $12.7 \pm 2.5 \mathrm{~mm}\left(0.5 \pm 0.1\right.$ in) $\mathrm{H}_{2} \mathrm{O}$ above the trip value.

10.14.4 SLOWLY ADJUST the DEADBAND potentiometer CCW until the alarm relay is energized.

10.14.5 VERIFY the red TRIP LED is OFF.

10.14.6 SLOWLY DECREASE the flow until the alarm trips.

10.14.7 VERIFY that the alarm trips at $5.6 \pm 2.8$ SLM $(0.2 \pm 0.1$ SCFM).

10.15 RESET the flow to 14.1 SLM (0.5 SCFM). 
HNF-SD-WM-OMM-029, REV. 0

PAGE 35 OF 37

\section{APPENDIX B}

ALARM SET POINTS 
STANDARD HYDROGEN MONITORING SYSTEM

PROCESS VALUES AND ALARM SET POINTS

MEASURED/CONTROLLED PROCESS

Main Sample Flow Rate

Grab Sample Flow Rate

Calibration Gas Flow Rate

Main Sample Gas Pressure

Sample Gas HT Cont. Temp.

Cal. Gas HT Cont. Temp.

Enclosure Heater Cont. Temp.

Enclosure A/C Cont. Temp.

PROCESS ALARM SET POINTS

Main Sample Flow Rate (FSL)

High Hydrogen (NASH 054/055)

Sample Gas Low Temp. (TSL)

Calibration Gas Low Temp. (TSL)

Enclosure High Temp. (TSHL)

Enclosure Low Temp. (TSL)

\begin{tabular}{|c|c|c|}
\hline$\frac{\text { PROCESS RANGE }}{0-45.3 \text { SLM }}$ & $\frac{\text { NOM. VALUE }}{14.1 \text { SLM }}$ & $\frac{\text { TOLERANCE }}{ \pm 2.8 \text { SLM }}$ \\
\hline
\end{tabular}

$0-1130 \underset{(0-40 \text { SCFH })}{226 \text { SLM }}(8 \mathrm{SCFH})$

\pm 2.8 SLM

$( \pm 0.1 \mathrm{SCFH})$

$0-70.8$ SLH $(0-2.5 \mathrm{SCFH})$

56.6 SLH

(2 SCFH)

$\pm 2.8 \mathrm{SLM}$

$( \pm 0.1 \mathrm{SCFH})$

N/A

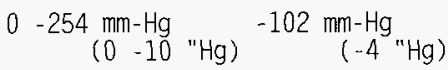

$4.4-65.6{ }^{\circ} \mathrm{C}$ (40-150 $\left.{ }^{\circ} \mathrm{F}\right)$

$51.7^{\circ} \mathrm{C}$ $\left(125^{\circ} \mathrm{F}\right)$

$\pm 1.1{ }^{\circ} \mathrm{C}$ $\left( \pm 2^{\circ} \mathrm{F}\right)$

$4.4-65.6^{\circ} \mathrm{C}$ $\left(40-150^{\circ} \mathrm{F}\right)$

$51.7^{\circ} \mathrm{C}$

$\left(125^{\circ} \mathrm{F}\right)$

$\pm 1.1{ }^{\circ} \mathrm{C}$

$\left( \pm 2{ }^{\circ} \mathrm{F}\right)$

$\begin{aligned} \pm 1.1{ }^{\circ} \mathrm{C} & \\ & \left( \pm 2{ }^{\circ} \mathrm{F}\right)\end{aligned}$

$\left(0-100^{\circ} \mathrm{F}\right)$

$26.7{ }^{\circ} \mathrm{C}\left(80^{\circ} \mathrm{F}\right)$

$32.2^{\circ} \mathrm{C}$

(50-131 $\left.{ }^{\circ} \mathrm{F}\right)$

${ }^{\circ} \mathrm{C}\left(90^{\circ} \mathrm{F}\right)$

$\pm 1.1^{\circ} \mathrm{C}$

$10-55^{\circ} \mathrm{C}$

TOLERANCE

$\frac{\text { NOMINAL VALUE }}{11.3 \mathrm{SLM}}$

$(0.4$ SCFM)

$( \pm 0.1$ SCFM)

$0.625 \% \mathrm{H}_{2}$

$\pm 0.1 \% \mathrm{H}_{2}$

$18.3^{\circ} \mathrm{C}$

$\left(65^{\circ} \mathrm{F}\right)$

$\pm 1.1^{\circ} \mathrm{C}$

$$
\left( \pm 2{ }^{\circ} \mathrm{F}\right)
$$

$18.3^{\circ} \mathrm{C}$ $\left(65^{\circ} \mathrm{F}\right)$

$\pm 1.1^{\circ} \mathrm{C}$ $\left( \pm 2{ }^{\circ} \mathrm{F}\right)$

$37.8^{\circ} \mathrm{C}$ $\left(100^{\circ} \mathrm{F}\right)$

$\pm 1.1{ }^{\circ} \mathrm{C}\left( \pm 2{ }^{\circ} \mathrm{F}\right)$

$21.1^{\circ} \mathrm{C}$ (70 $\left.{ }^{\circ} \mathrm{F}\right)$ $\pm 1.1^{\circ} \mathrm{C}$ $\left( \pm 2^{\circ} \mathrm{F}\right)$ 
PROCESS INSTRUMENT RANGES

\begin{tabular}{|c|c|c|}
\hline$\frac{\text { PROCESS INSTRUMENT }}{\text { FE-057 }}$ & $\begin{array}{l}\frac{\text { RANGE }}{0-45.3} \operatorname{SLM} \\
\qquad(0-1.6 \text { SCFM (Nom. ) ) }\end{array}$ & $\frac{\text { CAL. ACCURACY }}{ \pm 0.5 \% \text { FS (Cal. Not Req.) }}$ \\
\hline FIV -052 & $\begin{array}{l}0-1132 \mathrm{SLH} \\
(0-40 \mathrm{SCFH})\end{array}$ & $\pm 2 \%$ FS (Cal. Not Req.) \\
\hline FIV -056 & 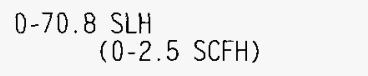 & $\pm 10 \%$ FS (Cal. Not Req.) \\
\hline FIT-057 & $\begin{array}{l}0-254 \mathrm{~mm} \mathrm{H}_{2} \mathrm{O} \\
\left(\mathrm{O}-1 \mathrm{O} \text { In } \mathrm{H}_{2} \mathrm{O}\right)\end{array}$ & $\pm 0.5 \% \mathrm{FS}$ \\
\hline PDIT-060 & $\begin{array}{l}0-6350 \mathrm{~mm} \mathrm{H}_{2} \mathrm{O} \\
\left(\mathrm{O}-250 \text { In } \mathrm{H}_{2} \mathrm{O}\right)\end{array}$ & $\pm 0.5 \% \mathrm{FS}$ \\
\hline NR-054 & $4-20 \mathrm{~mA}$ & $\pm 1 \%$ FS \\
\hline NIT-052 & $0-10 \% \quad \mathrm{NH}_{3}$ & $\pm 10 \%$ of reading \\
\hline NIT-054 (System) & $0-10 \% \mathrm{H}_{2}$ & $\pm 0.25 \% \mathrm{H}_{2}, \pm 5 \% \mathrm{FS}$ (Std Gas) \\
\hline NIT-054 (Output) & 4-20 mA & $\pm 0.5 \% \mathrm{FS}$ \\
\hline NIT-055 (System) & $0-1 \% \mathrm{H}_{2}$ & $\pm 0.25 \% \mathrm{H}_{2}, \pm 5 \% \mathrm{FS}(\mathrm{Std}$ Gas $)$ \\
\hline NIT-055 (Output) & $4-20 \mathrm{~mA}$ & $\pm 0.5 \% \mathrm{FS}$ \\
\hline PDI - 051 & $\begin{array}{l}0-1524 \mathrm{~mm} \mathrm{H}_{2} \mathrm{O} \\
\quad\left(0-60 \text { In } \mathrm{H}_{2} \mathrm{O}\right)\end{array}$ & $5 \%$ FS (Increasing) \\
\hline PI -053 & $\begin{aligned} 0 \text { to } & -760 \mathrm{~mm} \mathrm{Hg} \\
& (0 \text { to }-30 \mathrm{In} \mathrm{Hg})\end{aligned}$ & $\pm 5 \%$ FS \\
\hline
\end{tabular}




\section{DISTRIBUTION SHEET}

\begin{tabular}{|c|c|c|c|c|c|}
\hline \multirow{2}{*}{$\begin{array}{l}\text { TO } \\
\text { DISTRIBUTION }\end{array}$} & \multirow{2}{*}{\multicolumn{3}{|c|}{$\begin{array}{l}\text { From } \\
\text { B.L. Philipp SESC }\end{array}$}} & \multirow{2}{*}{\multicolumn{2}{|c|}{ Page 1 of 1}} \\
\hline & & & & & Date $5 / 12 / 97$ \\
\hline \multirow{2}{*}{\multicolumn{4}{|c|}{$\begin{array}{l}\text { Project Title/Work Order } \\
\text { Standard Hydrogen Monitoring System-E Operation and Maintenance } \\
\text { Manua } 1\end{array}$}} & \multirow{2}{*}{\multicolumn{2}{|c|}{$\begin{array}{l}\text { EDT No. } 619514 \\
\text { ECN No. }\end{array}$}} \\
\hline & & & & & \\
\hline Name & MSIN & $\begin{array}{c}\text { Text } \\
\text { With } \\
\text { All } \\
\text { Attach } \\
\text {. }\end{array}$ & $\begin{array}{l}\text { Text } \\
\text { Only }\end{array}$ & $\begin{array}{c}\text { Attach. } \\
/ \\
\text { Appendi } \\
x \\
\text { Only }\end{array}$ & $\begin{array}{l}\text { EOT/ECN } \\
\text { Only }\end{array}$ \\
\hline \multirow[t]{2}{*}{$\begin{array}{l}\text { T.C. Schneider } \\
\text { D.D. Tate } \\
\text { J.R. Bunch } \\
\text { B.L. Aftanas } \\
\text { M.F. Erhart } \\
\text { R.L. Schlosser } \\
\text { W.L. Adams } \\
\text { S.U. Zaman } \\
\text { B.L. Philipp (3) }\end{array}$} & $\begin{array}{l}\text { L6-37 } \\
\text { L6-37 } \\
\text { L6-37 } \\
\text { L6-37 } \\
\text { R1 }-51 \\
\text { R1 }-56 \\
\text { S5-12 } \\
\text { R3-01 } \\
\text { L6-37 }\end{array}$ & $\begin{array}{l}x \\
x \\
x \\
x \\
x \\
x \\
x \\
x \\
x\end{array}$ & & & \multirow[t]{2}{*}{$x$} \\
\hline & A3-88 & $x$ & & & \\
\hline
\end{tabular}

